that part of their producing gas may be even far outside the usually considered limits of everything belonging to the earth.

M. Thollon, indeed, gives a view of the " $\mathrm{B}$ " region, "as," he says, "it would appear if observed outside the earth's atmosphere"; and thercin he shows every line constituting our magnificent earthly constellation "Great B," absolutely wiped out of existence - a few ultra-faint, accidentally intruding solar metallic lines alone excepted. But how has the eminent savant obtained that view? Not by ascending in a balloon, or up the sides of a high mountain above all the grosser atmosphere, and seeing that it was so, but merely by observin s some small amount of difference of effect, at two slightly different degrees of large zenith distance, viz. $60^{\circ}$ and $80^{\circ}$, at the Observatory of Nice.

Two points, however, alone, will never enable a curve to be drawn on their sole authority ; and as a curve of effect is what the investigation now requires, $M$. Thollon's hitherto merely duplex observations will acquire a far greater power of conviction for other men's minds, if he will kindly supplement them with others at $20^{\circ}$ Z.D., or as near to it as the latitude of Nice will allow him at time of summer solstice. Still more would he make us all his debtors if he would repeat those three angular directions at three successive stations at greater hypsometric aititudes; duly remembering that while every one knows that water-vapour and oxygen (the gaseous parentage of " B" according to the grand experiments of M. Egoroff) do exist in the earth's atmosphere, that does not, by itself, therefore render them impossible in greater or le:s quantity to the outer region of the sun's envelopes; or, in a highly attenuated degree, to the $92,000,000$ of miles of space between.

15, Royal Terrace, Edinburgh, September 27

\section{Shifting of the Earth's Axis}

WITH reference to the letter of Mr. W. M. Flinders Petric (NATURF, September 25, p. 5I2), I would remark that there has been no sensible change in the latitude of Greenwich (as found by observations of circumpolar stars) during the last fortyseven years, a period nearly twice as long as that covered by the Pulkowa observations which M. Nyrén has discussed. In a paper on the "Systematic Errors of the Greenwich North Polar Distances" (Mem. R.A.S, vol. xlv.), I have exhibited the results for the co-latitude of the centre of the Greenwich transit-circle for each year and for groups of years from 1836 to 1877 reduced to the same refractions throughout (Bessel's), and corrected where necessary for index-error of the thermometer, and the accordance of the individual results is as close as can be expected, when allowance is made for the systematic errors to which all observations are liable, but which are usually ignored in estimating theoretically the probable errors of mean results. It may suffice if I here give the results for co-latitude for three periods of years :-

$$
\begin{aligned}
& \mathbf{I} 836-49 \text { mean co-latitude } 38^{\circ} 3 \mathrm{I}^{\prime} \begin{array}{r}
2 \mathrm{I}^{\prime \prime} \cdot 85 \\
2 \mathrm{I}^{\prime \prime} \cdot 87 \\
\mathbf{1} 85 \mathrm{I}-65 \\
\mathbf{I} 866-83
\end{array} \\
& 2 \mathrm{I}^{\prime \prime} \cdot 85
\end{aligned}
$$

The first and last results are identical and are absolutely inconsistent with Mr. Petrie's supposed increase of the Greenwich colatitude of $\mathbf{I}^{\prime \prime}$ or more in a century.

Royal Observatory, Greenwich, S.E., September 27

\section{The Sky-Glows}

FrOM the great purity of the sky this evening, and from the flatness of the horizon westwards, on the line of the Great Northern Railway between Huntingdon and Hitchin, the sunset glow was of a very beautiful description. At five minutes before six (watch-time, three or four minutes slow) the sun set; and it was no sooner hidden than a parhelion-like patch of white light, $6^{\circ}$ or $8^{\circ}$ in diameter, brighter than the rest of the sky, occupied a place $10^{\circ}$ or $15^{\circ}$ above the sunset point of the horizon, and continued shining there with pearly brightness for about ten minutes. The horizon-line became edged at the same time with bright red, melting abruptly away upwards into orange, and higher up into a field of yellow light round the lucid spot. At 6.5 this spot's white light began to acquire a rosy tinge, and during the next ten minutes, until 6.15, it became intensely rosecoloured, preserving its definite place unchanged in the upper expanse of yellow; a vivid golden oriole-yellow stripe some degrees broad divided it from the red fringe along the horizon, the dazzling gold colour shading exquisitely into the fiery red below and rosy red above, and deriving itself from the latter a bronze-like greenish cast in its bright golden hue by contrast.

By 6.15 the rosiness of the bright spot had extended upwards and outwards from its centre, and was now blended in its colour and confines with the yellow band and red fringe below it, until the whole presented a conflagration or red aurora-like outburst of light in the west, $20^{\circ}$ or $25^{\circ}$ high, and extending $45^{\circ}$ or $50^{\circ}$ in base along the horizon.

The yellow belt was fading out of this glory, and the brightness and rosiness of its upper part was fast disappearing, when at $6 . \mathrm{I} 5$ there appeared, with extreme quickness in the brighter base, dark intervals dividing it into upward radiating diverging beams of light, which rapidly acquired such fixed breadths and distinctness that I casily counted six or eight separate beams nearly equidistant from each other, and of equal lengths and strengths, marking out plainly by their divergence the sun's place, and the considerable depth to which it had already sunk below the horizon. The two outer ones only of the beams, on the northern side, were a little confused together, and marred the symmetry which the whole presented, but the full number of their display was several times counted over during the ten minutes-until 6.25 -that they continued visible. They were about $15^{\circ}$ long from their bases, and extended across and usurped to themselves the light of what had been the golden-yellow belt ; but they gradually shortened and became dull red when at the latter hour the horizon assumed the red appearance which it usually presents some time after sunset. The above striking phases of the glow, - the white spot, the rose-red one, and the streamers,--occupied just ten minutes each, and the unusual aspect of the sky ceased entirely just thirty minutes after sunset.

The patch of whitish light observed this evening had all the appearance of a true, but extended and diffused, mock sun of some description; and I have noticed the peculiarity before, in the sunset glows of last winter and spring, whenever I had an opportunity to see the sky and watch their early phase just after sunset; but crystals of ice being then plentiful in cirrus, the evidence of the mock sun's formation by non-aqueous dust in the atmosphere was not so strong as now, when it has recurred after a long continuance of a summer temperature which has been unusually high. It is also singular and curious that the rosy tint began in the white-glow spot, and spread evenly outwards from it as a centre, as the extent and intensity of this remarkable colour grew and increased.

Appearing as the white spot does, when I have seen it, at a pretty fixed height of not less than about $12^{\circ}$ from the horizon as soon as the sun has set, it seems difficult to reconcile its presence at such an altitude with a theory of its production by reflection of the sun's horizontal rays from fine films or laminæ of floating glassy dust, unless descending equatorial currents, perhaps, in those extremely stable heights may have a sensible inclination downwards from the west, and may tilt the films' under sides in a direction corresponding with that of the current slightly towards the sun?

With regard to the diverging beams, they are also, perhaps, not quite ordinary, irregularly produced straight lines of radiation ; but secmed by their symmetry to be connected, at least in the origin of the shadow-gaps which formed them, with evenly ruled stripes or pleats of the cirrus, and of loftier hazc, in this case directed, it seemed, nearly east and west. With such hazebands and stripes directed rather more sou h-westerly, or about towards the point of winter sunset, and intersected also with slightly slanting systems of striation, I constantly noticed the sky in Newcastle-on-Tyne, during the prevalence last winter and spring of the repeated sunset glows, to be for weeks and months more or less constantly and uniformly, but in general weakly and dimly, streaked and furrowed over. Either an unusually steady current was prevailing in the upper air ; or else a permanent current there, and long lines of aerial disturbances troubling its streams were made more visible and conspicuous than ordinary, by exceptional radiation, or some other unusual refrigerating and haze-engendering cause, depriving the upper air of its transparency, during the time of the sky's presenting such unusual appearances in what Quetelet named and considered to be the "stable" or untempestuous upper regions of the atmosphere.

Whatever may be the explanation of the streamers and of the white glare-spot, observations may perhaps be made of them under even more favourable conditions than occurred this evening, and they would then possibly give a little help towards arriving at some further conclusions both as regards the crystalline or other nature of the haze-causing substance, and as to the 